\title{
Actual Technical Condition Assessment of A Motor-Wheel Gear of A Dump Truck Belaz Based on the Operating Oil Parameters
}

\author{
Andrei Kudrevatykh ${ }^{1}$, Andrei Ashcheulov ${ }^{1, *}$, Alena Ashcheulova ${ }^{2}$, Olesia Karnadud $^{1}$, and \\ Ludger Rattmann ${ }^{3}$ \\ ${ }^{1}$ T.F. Gorbachev Kuzbass State Technical University, 65000, Kemerovo, Russia \\ ${ }^{2}$ Kemerovo State Agricultural Institute, 650056, Kemerovo, Russia \\ ${ }^{3}$ Technische Hochschule Georg Agricola (THGA), Bochum, Germany
}

\begin{abstract}
One of the most important indicators of mining complexes are reliability and durability of their components. Studies have shown that the largest amount of mine dump truck down time occurs due to unforeseen failures of a motor-wheel gear. The introduction of additional technological processes to diagnose the actual technical condition of a gear in the maintenance procedure will make it possible to maintain directly the state of its component parts with in-place manner. The method of diagnosing the condition of a motor-wheel gear is based on physical and chemical analysis of oil, as well as its temperature control. During open pit machinery exploitation, various mechanical impurities of wear products of rubbing surfaces accumulate in the operating oil, so it is possible to predict the degree of wear of gear units and mechanisms based on these mechanical impurities. The introduction of this method in production will significantly reduce the down time of dump trucks, thereby increase the productivity of the enterprise and reduce repair costs.
\end{abstract}

\section{Introduction}

The surface mining takes the leading position in mining industry due to such factors as safety, efficiency and the highest productivity. What is more, in the nearest future this type of mining will retain its leading positions. Despite these advantages over other mining methods, surface mining has a number of drawbacks, namely a large amount of down time of excavator-car complexes, the reduction of which will significantly increase the productivity of mining machines and equipment and reduce the cost of production [1].

Due to low reliability of mining equipment, the necessary costs for its maintenance increases, and the costs associated with repairs over its entire service life exceeds the cost of the equipment itself in several times, therefore it is necessary to improve the quality of the mining complex, the main of which is its reliability. Full use of the individual potential of each machine, as well as a significant increase in the reliability of the entire mining complex as a whole is possible due to the introduction into the technological process of

\footnotetext{
${ }^{*}$ Corresponding author: ascheulovas@kuzstu.ru
} 
another fundamentally new operation in diagnosing the actual technical condition of the components and units of the excavator-automotive complex [2]. Carrying out of this operation is possible by various methods, the choice of which depends on many factors: the availability of necessary equipment at the enterprise, trained and certified personnel and so on.

All large machine-building enterprises continuously carry out improvements in structures of units and mechanisms of coal-mining machines. Despite this, the equipment is used in very difficult conditions and suffers constant enormous loads during operation; it leads to the failure of important units such as dump trucks motor-wheel, rotary gears of excavators.

During mechanisms and machines operation, there are two closely interconnected with each other processes inside units and mechanisms: friction and wear [3-4]. When operating, the oil interacts with rubbing surfaces, as a result oil physical and chemical properties change. These changes are indicators of the actual technical condition of mechanisms under study, which can be estimated during oil analysis without dismantling the unit or mechanism.

Studies have shown that the decrease in reliability of the unit and mechanism of mining complexes occurs not only due to a decrease in their resource during operation due to wear of rubbing surfaces, but also when the physical and chemical properties of oils change, when the oils accumulate metallic impurities of wear products during operation [5].

According to all mentioned above, the main task is to develop a method for monitoring the physical and chemical properties of the operating oils, and a method of monitoring the actual technical condition of the units and mechanisms of mining complexes. The implementation of this method will make it possible to predict unforeseen equipment failures due to the failure of one of the components of the excavator-vehicle park.

There is a tendency in coal industry to increase the volume of traffic by means of motor transport, including Kuzbass open pits. The largest quantitative increase is observed in such companies as "Kuzbassrazrezugol", "Sokolovskaya" [6]. Such high growth rate is because coal mining enterprises prefer the increased reliability and flexibility of mining equipment, lower maintenance costs, as well as high mobility and flexibility, small size and autonomy. Thus, in Kuzbass open pits the number of dump trucks has recently increased by 32, which corresponds to $6.81 \%$ of their total number. This is due to the traffic growth.

\section{Results and discussions}

The increase in such indicators as reliability and durability of mining complexes affects directly the reduction of down time. These down time is possible for several reasons: due to controlled and uncontrollable factors. In coal mines, productivity increase is possible only by influencing on controlled factors. During the operation of dump trucks, their units and mechanisms there is the change in their technical condition due to a number of reasons: the effects of external forces, such as weather conditions, the environment in which the equipment operates, and internal forces - this is wear, deformations and physical and chemical changes of materials [7-9].

While investigating the number of failures that occurred at OJSC "Kuzbassrazrezugol" for the period under study among BelAZ dump trucks, there is a tendency of significant increase in transport down time. If to compare with previous years, the number of down time has increased by 2.6 times, which led to a significant decrease in their productivity, and therefore, increased losses of rock mass. The analysis of dump trucks down time causes revealed that the greatest number of down time was due to the failure of a motor-wheel gear, which amounted to 64,238 operating hours, which is $18.8 \%$ of the total down time of the dump trucks in this enterprise. Thus, there is a need to develop and implement measures 
to monitor the actual technical condition of motor-wheel gears of dump trucks, in order to reduce unexpected equipment failures.

In order to determine the rate of accumulation of metallic impurities in the oil of a gear of a motor-wheel dump truck BelAZ-75131, a series of experiments were conducted. The quantitative value of oil contamination by wear products of rubbing surfaces was determined using the multichannel photometric system MFS-7. To identify the time interval for oil sampling, an additional series of experiments were conducted at various intervals. The most optimal period was 50 operating hours of a dump truck. This period allows observing in dynamics the accumulation of metallic impurities in oil without interfering the operation of the technology itself.

The sampling was carried out using a syringe sampler through a special filler hole on the gear cover. The results of the physical and chemical analysis of oil samples on the content of metal impurities in it are shown in Figure 1.

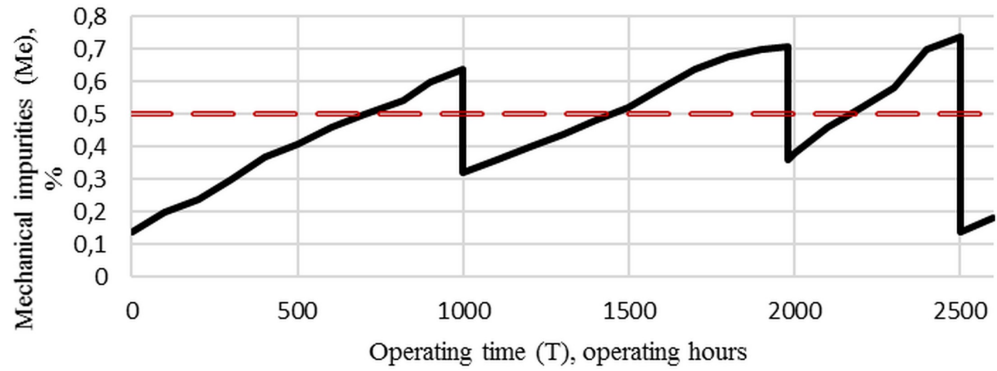

Fig. 1. The diagram of the metallic impurities content in oil of a dump truck gear.

The operating time (in operating hours) of a dump truck is shown on the diagram horizontally, and the content of metallic impurities in the transmission oil of the motorwheel gear is shown vertically, in percentage. When analysing the graphics, extremes are observed with operating time of 1000 and 2000 operating hours, which are explained by the necessity to add transmission oil by pouring it. At the highest extremum, at production time of 2500 operating hours, there is a significant decrease of impurities in the oil, since according to the requirements of the technical regulations for servicing a dump truck; at this time, it is necessary to replace the oil in a motor-wheel gear.

A series of experiments showed that the accumulation of wear products of rubbing surfaces in transmission oil occurs in a linear relationship with relatively fast speed, while the graphics shows a horizontal line corresponding to critical concentration of impurities, at which wear of units and parts of a gear occurs. Thus, it is clear from the graphics that, despite oil adding, a gear works more and more when the critical concentration of metallic impurities is exceeded, that affects its reliability and durability negatively.

This study also had the second goal, namely the application of this methodology to monitor the actual technical condition of a motor-wheel gear of a dump truck. However, a number of negative factors do not allow to apply this technique fully, as when the oil is completely changed, all of oil is renewed, as a result, the concentration of metallic impurities sharply decreases, on the basis of these impurities the state of a gear is assessed. The physical and chemical analysis of the oil makes it possible to diagnose a gear only in a short time period; it makes it impossible to predict the change in the state of the units and mechanisms in the future.

Based on the mentioned above, we can conclude that it is necessary to introduce additional methods to monitor the condition of parts and components of the units under investigation. Therefore, additional studies have been carried out to identify the most 
optimal method of in-place diagnostics of a gear. The method of temperature control of operational oil has proven itself as the most effective.

Temperature control of the operating oil in a gear consists in measuring its temperature continuously during the operation of a dump truck. As it is well known, there is wear when rubbing surfaces are interacting, and as a result, there is separation of small particles from parts; these metallic impurities, when get into oil of a gear, deteriorate oil physical and chemical properties, including lubricating properties. Thus, when oil parameters are changed, the wear process occurs more intensively and local overheating occurs, this overheating in turn affects the increase in oil temperature. The installed temperature sensor in a box of motor-wheel gear of a BelAZ dump truck allows for continuous monitoring of the state of its units and mechanisms, based on the temperature readings of transmission oil. The purpose of the study is to determine the dependence of the temperature of the operating lubricant on the amount of impurities in it.

For experiments, it was adopted, based on previous studies, the time interval of 50 operating hours, but in this case not only the sampling of the oil is taken, but also the temperature is measured. Based on the results of physical and chemical and temperature analyses, data was obtained on the temperature variation of the operating oil ( $\mathrm{t}$ ) from the operating time (T) of a dump truck, and the amount of metallic impurities in oil (Me) from the operating time.

A graphic illustration of changes in the summer time is presented in Figure 2.

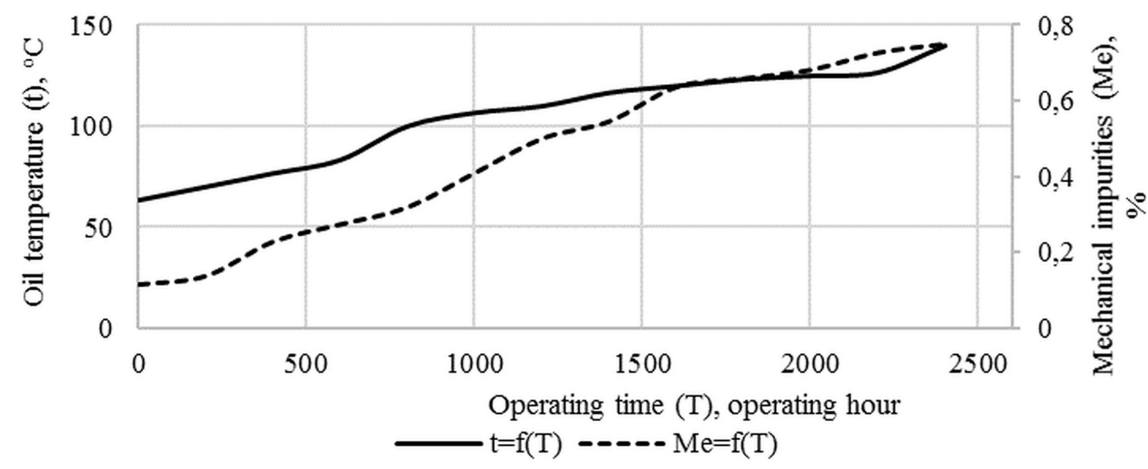

Fig. 2. Gear indicators of a motor- wheel BelAZ.

From the graphics presented in Figure 2, it can be seen that with time there is a gradual increase of amount of metallic impurities in oil, which is confirmed by previous experiments. In addition, there is an increase in temperature of the operating oil with an increase in the operating time of a motor-wheel gear. Therefore, it is necessary to verify the theory proposed above concerning the direct dependence of the lubricant temperature on the content of impurities in it. To do this, it is necessary to conduct a correlation-regression analysis of the data obtained in the result of the conducted experiments, and not only in the summer period, but in all others periods as well.

In order to identify a more complete dependence of the considered parameters, it is also necessary to add the influence of an external factor on the temperature of oil and the content of metallic impurities in it, namely the atmospheric temperature as it will directly affect the physical and chemical properties of the lubricant [10]. Thus, in order to determine the influence of the atmospheric temperature, experiments were carried out during the year, and the results were recorded in a pivot table.

To determine the power of influence of the dump truck operation time and the atmospheric temperature on the parameters of the used transmission oil in a gear, according 
to the data obtained during the experiment, a correlation analysis was performed, the coefficients of which are shown in Table 1.

Table 1. Correlation parameter results (Cheddock scale).

\begin{tabular}{|c|c|c|c|c|}
\hline & Oil temperature & Operating time & $\begin{array}{c}\text { Metallic } \\
\text { impurities }\end{array}$ & $\begin{array}{c}\text { Atmospheric } \\
\text { temperature }\end{array}$ \\
\hline Oil temperature & 1 & & & \\
\hline Operating time & 0.531 & 1 & & \\
\hline $\begin{array}{c}\text { Metallic } \\
\text { impurities }\end{array}$ & 0.902 & 0.632 & 1 & \\
\hline $\begin{array}{c}\text { Outside } \\
\text { temperature }\end{array}$ & 0.606 & 0 & 0.315 & 1 \\
\hline
\end{tabular}

Analysing the data obtained it can be concluded that all considered parameters have a sufficient effect on the lubricant temperature. Moreover, the greatest relationship is the amount of impurities in oil. According to the Cheddok scale, the interaction between the temperature in a gear and the atmospheric temperature is average. Moreover, the zero correlation coefficient between the operating time and the atmospheric temperature indicates that these two parameters do not influence each other, as they change independently of each other. Thus, based on the results of the correlation analysis, it can be concluded that all parameters are selected correctly, there is a strong correlation, therefore, they can be used for further regression analysis.

To create a mathematical model of the temperature change of the operating oil in a gear of a BelAZ dump truck the correlation analysis is not enough. Therefore, according to the experimentally obtained data, a regression analysis was performed to identify the numerical dependence of the lubricant temperature $(\mathrm{t})$ on such parameters as: dump truck operation time (T), the amount of metallic impurities in the lubricant (Me) and atmospheric temperature $\left(\mathrm{t}_{\mathrm{oc}}\right)$. The results of correlation analysis are presented in a mathematical model (1):

$$
\mathrm{t}=42.47+0.002 \mathrm{~T}+108.41 \mathrm{Me}+0.88 \mathrm{t}_{\mathrm{oc}}
$$

The mathematical model of the temperature variation of the operating oil from external parameters describes this process with a reliability of $96.7 \%$, and the unaccounted factors influence only $3.3 \%$. This indicator means that the model obtained in result of the regression analysis is reliable. This is also seen by the test for adequacy from the Fisher's Fcriterion.

Calculating from equation (1) the amount of metallic impurities in the lubricant, we get:

$$
\mathrm{Me}=\frac{\mathrm{t}-\left(42.47+0.002 \mathrm{~T}+0.88 \mathrm{t}_{\mathrm{oc}}\right)}{108.41}
$$

Because in everyday operation it is not always possible to carry out a physical and chemical analysis of the operating oil, and not every open pit has equipment for this diagnostic, the lubricant temperature of a gear is chosen as the determining parameter. Therefore, using the mathematical model (2) it is sufficient to measure the temperature of the oil in a gear and the environment, calculate the amount of metallic impurities, comparing the obtained value with the critical one. Therefore, you can judge the actual technical condition of both a gear of a motor-wheel dump truck BelAZ and its components. 


\section{Conclusion}

The increase in reliability and durability of BelAZ dump trucks reduces unplanned down time, unforeseen failures of their components and mechanisms, and increases the overall performance of the entire coal-mining complex. The introduction of in-place diagnostics in the production line of equipment maintenance will significantly reduce losses in the volume of coal mining, and reduce the cost of coal itself, which will positively affect the economic growth of coal mining industry. Due to the investigations aimed to determine the influence of external factors on the accumulation of metallic impurities in the operating oil, a mathematical model describing this process was obtained. Its use in production will allow tracking the actual technical condition of BelAZ motor-wheel gears in dynamics, and foresee a possible unforeseen failure, which in turn optimizes the work of the chief mechanic of an enterprise, will allow correcting the plan for maintenance and repair of the motor park.

When conducting additional experiments, it is possible to introduce this method of inplace diagnostics of the actual state of units and mechanisms to other facilities of various mining equipment. Thus, only a small addition to the technological maintenance process will reduce downtime, reduce the number of failures, and as a result, increase the productivity of the entire mining complex.

\section{References}

1. S. Zhironkin, G. Barysheva, A. Khoreshok, M. Tyulenev, M. Hellmer, Innovative Technologies in Engineering, 12, 127 (2016)

2. D. Basset, M. Herman, J. Martin, ASLE Transactions, 4:27, 380 (1984)

3. Q. Sunqing, D. Junxiu, Ch. Guoxu, Lubricating Science, 3:11, 165 (1999)

4. A. Efremenkov, A. Khoreshok, S. Zhironkin, A. Myaskov, IOP Conference Series: Earth and Environmental Science, 50, 012009 (2017)

5. I. Prigogine, R. Herman, Amer (Elsevier Publ. Co., Amsterdam, 1971)

6. D. Stenin, N. Stenina, A. Bakanov, Coal in the 21st Century: Mining, Processing and Safety, 1, 256 (2016)

7. D. Landheer, Ostfildem: Techninshe Akademie Esslingen Druck, 1, 38 (1986)

8. D. Stenin, A. Kulpin, E. Kultayev, E. Kulpina, V. Borovtsov, Coal in the 21 st Century: Mining, Processing and Safety, 1, 116 (2016)

9. Q. Sunqing, D. Junxiu, Ch. Guoxu, Lubricating Science, 3:11, 165 (1999)

10. D. Stenin, N. Stenina, E3S Web Conf., 41, 03012 (2017) 